\title{
Correlation between Motivational Orientations and Self-Control on Learners' English Achievement
}

\author{
Marningsih Sadik ${ }^{1}$ \\ ${ }^{1}$ Department of English Language Studies, Universitas Hasanuddin, Makassar, Indonesia \\ *marningsihsadikoo@gmail.com
}

\begin{abstract}
The objectives of this study are to probe the correlation between motivational orientations and self-control on Learners' English achievement as evidenced by the TOEFL score, and to investigate which of the two psychological aspects is more dominantly contributive in affecting the learners' achievement. It employed mixed-method design which combined qualitative and quantitative methods to measure the data elicited from distributed questionnaires and interviews. The researcher purposely took English Department Students as the participants who had attended TOEFL Test. Questionnaires were distributed to measure their motivation and self-control in relation to their English learning. Besides, from the 32 participants who returned the questionnaire, there were only 10 of them chosen to become the representatives in the interview session. The finding showed the correlation between both motivational orientations exhibited a great difference. Integrative motivation has a positive correlation $(r=0.371)$ with the TOEFL score although classified as moderate while the instrumental one is negatively correlated $(r=-0.240)$. This means that integrative motivation is relatively more contributive to English achievement. The significant value of the integrative motivation was lower than the confidence level (0.05; Sig. INT $=0.037)$, whereas the significant level of instrumental motivation showed higher than the confidence level (Sig, INS $=0.186$ ) indicating that instrumental motivation and the learners' achievement in English were not significantly correlated. Meanwhile, self-control has a strong correlation to the TOEFL score $(r=0.532)$ with confidence level higher than the significant value obtained (0.02).
\end{abstract}

Key words: Correlation, motivational orientations, self-control, TOEFL.

\section{Introduction}

Motivation has been massively proven as the most prohibiting parameter determining the successful English learners. Even though a number of efforts have been extracted to facilitate the learners in improving their English competence, having no motivation will absolutely fail all those efforts. Motivation is a fundamental base of doing or achieving a target goal. Connecting to the language learning process, motivation is considered as the main predictor to determine the success of mastering a new language, and becomes the basic willingness for learners to why and how they learn it. This is in line with Parsons et. al, defines that motivation is a crucial component or factor in the process of learning the language to reach the target goal [1]. Motivation, based on the most utilized theory developed by two Canadians researchers named Gardner and Lambert, is categorized into two, namely instrumental motivation and integrative 
motivation. Instrumental motivation is a desire to learn a second language influenced by some particular needs such as to get a prestigious job, to pursue study, or just want to pass a course. Whereas, Integrative motivation is recognized as a pure interest carried out by the learners in order to be engaged to the community where the language is spoken.

Masses of research have been conducted concerning these two different classifications of motivation to what extent they contribute to learners' English competence. Zanghar conducted research to probe the motivation of the Undergraduate Libyan Students towards learning English as a foreign language [2]. It was found that the students' motivation integratively achieved more than the one who got the instrumental motivation. Zanghar further explained that this case was due to the integratively motivated students having more genuine willingness to keep learning the language than the instrumental one who did want to learn the language for personal purposes. However, a distinct result was discovered by Altasan who also conducted research focusing on investigating the motivational orientation towards learning English [3]. Altasan found that instrumentally motivated students had more significant achievement compared to the integrative ones.

Regarding those aforementioned findings, it can be inferred that the two motivational orientations have quite similar roles in affecting learner's English competence. Accordingly, the writer has a prior assumption that it is not actually the motivation that defines the learners' goal to master English, but it is more likely about what comes after the motivation to what extent the learners try to put their motivation into a real action, and how they manage themselves to sustain their motivation. In short, being motivated but not linearly done with a persistent action will be pointless. Thus, the writer inserted another possible factor that has the potential to affect learner's competence in English, that is self-control. Self-control, in detail, refers to the ability of humans in dealing with themselves to overcome unpredictable situations in doing something. In terms of the learning process, having a high self-control, a learner will keep maintaining the motivation to learn English among whatever undesirable circumstance happens. Many researchers have proved that self-control has a significant contribution to grasp a goal. Self-control has a magnificent role in defining successful students in their academic field. Self-control, according to her, can increase students' energy, make them study more, and develop their study routines that terminate their academic success [4]. The study of investigating the role of IQ and Self-control in defining students' achievement exhibited that self-control more positively correlated to the students' grade compared to IQ [5]. It has been suggested that intelligence helps students learn and solve problems independently of formal instruction, whereas self-control helps students study, complete homework, and behave positively in the classroom.

In correspondence with the two issues above, the writer through this present study would like to examine those two aspects to which of them provides more contribution to define the learners' success in English. The findings of this current research can provide a new insight to the scope of English language learning in terms of another factor that inhibits the learners to improve their English competence.

There are two main inquiries that the writer is trying to examine throughout the present study: 1) Is there any correlation between psychological aspect, self-control and motivational orientation, and Learners' English achievement?; 2) Which of the two independent variables; self-control and motivational orientation, is more dominantly contributive in defining the success of the English learners?.

To straightly forward to the main purposes of this research that is to prove that psychological aspects affect the learner's English achievement, these are the hypotheses that are being examined in this research; 1) Null Hypothesis (Ho) : Motivational orientations more positively correlate with Learners' English achievement than self-control and there is no significant values between the psychological aspects and Learners' English achievement; 2) Alternate Hypothesis (H1): Self-control more positively correlates with Learners' English achievement than the motivational orientations and there is significant values between the psychological aspects and Learners' English achievement.

\section{Theoretical Reviews}

\section{Motivation}

Motivation is a main predictor to determine the success of mastering a new language. It also becomes the basic willingness for learners to what intention they learn it. motivation deals with a need or desire that energizes and directs behavior. Gardner conceptualized motivation to an extent one strives to acquire the language because of the desire to do so and the satisfaction derived from it [6]. Henceforth, motivation can be considerably identified as one of the main factors affecting English language learners. Besides, having a certain goal through learning a new language can influence the way the learners conduct their attitude to learn it.

Therefore, motivation can also raise learners' enthusiasm, persistence and commitment in learning the target language in which those terms are strongly considered as the key determinant of success and failure through learning that language [7]. In addition, motivation is a crucial component or factor in the process of learning the language, so the term learning and motivation have the same important role in achieving the goal [1]. Connectedly, learning can make the learners gain new knowledge and skills while motivation pushes or encourages them to go through the learning process. 
Motivation itself is actually the case study of psychology, and it has been influenced by various psychological theories. Since it relates to human-being and is really intriguing to be explored more deeply, there have been many theories developed to figure out the basic essence of it especially if it is related to the process of learning a language. The most important aspect dealt with is the reasons why people learn particular languages which traditionally have been classified as instrumental and integrative orientation reflecting two orientations either particular self-needs like enhancing future prospect or social-cultural goal which relates to the needs of seeking for contacts with the target language speakers.

This concept was pioneered by two Canadians researchers [8]. They programmed by concerning the social issue occurring in the society where humans have the biggest role in reconstructing that concept which is strongly intended to demonstrate their psychological view in relation to the reasons for learning a new language. Since Gardner and Lambert invented and developed this theory in the 1960s, it has massively influenced the way scholars analyze people's motivational purpose in learning a second or foreign language. Furthermore, this social-psychological theoretical base, in row with its development, has been effectively focused on the future-oriented dimension in which it recently has become a frame to relate a person's desired and imagined future self-representation, [9]. In viewing the socio-psychological model, as having been mentioned, it is categorized into two points; instrumental and integrative motivation. They will be elaborated as follows:

\section{Instrumental motivation}

Instrumental motivation is a desire to learn a second language influenced by some particular needs such as to get a prestigious job, to pursue study, or just want to pass a course. In line with the opinion, according to Gardner and Lambert, instrumental motivation is affected by willingness to gain social recognition or economic advantages through knowing the target language [8]. In correspondence, it will direct the learners to make an effort for some operational reasons such as to get accepted in a goaled university, to have a great score in examination, to get a better career, or to go abroad for a certain functional purpose.

\section{Integrative motivation}

Integrative motivation is recognized as a pure interest carried out by the learners in order to be included to the community to which the language is learned. It is linearly defined as the desire to be a part of recognized or important members of the community or that society that speaks the second language. Learners having integrative motivation through learning the second language will gather with the language joyfully because they are not pressured by the promise of achieving some particular purpose. Consequently, they undoubtedly get easy to master the language.

Correspondingly, the two motivations above have an important role which surely will carry different senses to learners. Dorney addressed in his research about EFL students in Hungary [10]. He found that the students with higher levels of English had an integrative motivation, whereas those who had an instrumental motivation were more likely to have an intermediate proficiency in English. Furthermore, in some of the early research conducted by Gardner and Lambert, the result asserted that integrative motivation was viewed as being of more importance in a formal learning environment than instrumental motivation [11]. It was hypothesized by Gardner that an integratively motivated learner would tend to have more positive attitudes towards the target language; also this learner would be more likely to expend more effort in learning the language. Moreover, Dörnyei pointed out that instrumental motivation alone will not be enough to progress to more advanced levels, where integrative motivation appears to be a more important factor [12]. Instrumental motivation also has the same contribution to language achievement. Some scholars found in their research that being motivated instrumentally can also carry a good achievement of targeted language in which they focused on English as their dependent variable [13] [14]. Hence, varying types of motivation correlated with varying levels of proficiency.

\section{Self-control}

Self-control is a feeling and thought that establishes the self-awareness to be always on the regulated way to achieve a targeted goal. A simple illustration of self-control as follows stated by Duckworth [15].

The Fig illustrates that a student faces a self-control conflict when choosing between studying for a math test and scrolling through new photos in their Instagram feed. Scrolling through Instagram is extremely fun in the moment but not valued in the long run. In contrast, studying for the math test is not very fun in the moment but valued in the long run. Studying math and checking social media are mutually exclusive responses. More tellingly, it can be interpreted in figure (a) that studying is congruent with the academic goal of doing well in math, whereas checking social media is congruent with the goal of immediate pleasure. Whereas, in figure (b) doing well in math is related to the student's goal of becoming a doctor, whereas pleasure is primarily an end in itself. Self- control thus takes the form of enacting the impulse to study math while refraining from the impulse to check social media.

Based on the illustration above, it can be inferred that self-control is a self- regulation coming from self-awareness of being maintained with the future goal. Being controlled means having the self-endure to throw away the immediate pleasure and keep the long-term one. 


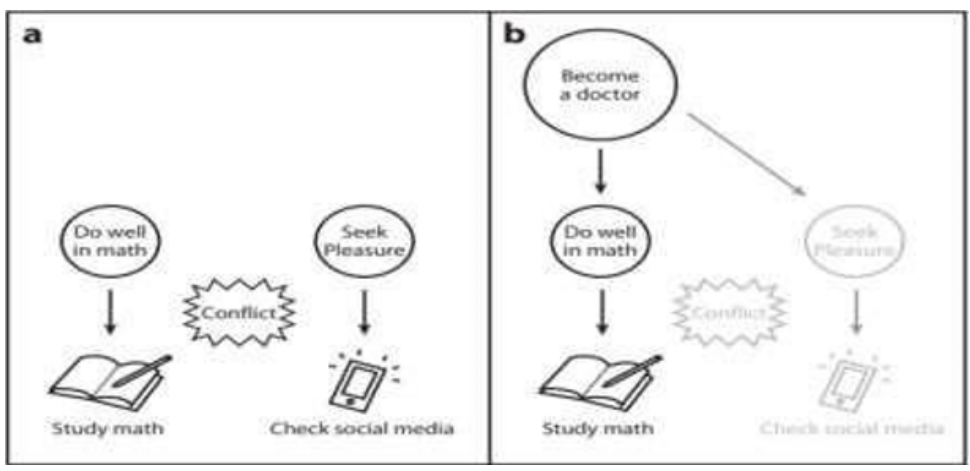

Figure 1. Self-Control Illustration!

In further, self-control can be distinguished in regards to the two related concepts. At first. Self-control is selfinitiated. The self-initiated is obtained from the feeling and thought that it is necessary to do in order to keep on target. For example, as the illustration pictured, the students who are exercising the self-control are those who always put away their phone as a temporary pleasure and choose to keep on learning. Self-control can be as the form of habits that is consciously self-initiated in the past by arranging plans and rules to achieve the goal. Self-control is a considerably chosen option that is notably more valuable in the long term run than the other options although the unchosen one is temporally more attractive [15]. There are three base concepts of self- control named The Self-Control Scale; first, regulating the root of thought such as forcing oneself to concentrate, altering moods or motions; next, restraining undesirable impulses; and achieving performance like making oneself persist. Those concepts are important to alter its states or behavior. More generally, breaking bad habits, resisting temptation, and keeping good self-discipline all reflect the ability of the self to control itself, and we sought to build our scale around them.

\section{Methodology}

Design

This present study employed mixed-method design which combined both qualitative and quantitative approach with its primary model called Explanatory sequential mixed method or QUAN-Qual Model [16]. This model has the researcher first conduct quantitative research and analyze it using descriptive and inferential analysis, and then build the result to explain the detailed information using qualitative methods. This method was considerably selected in order to strengthen and to increase the reliability and validity of the result elicited.

In the quantitative method, the researcher administered descriptive and inferential analysis by adapting product moment correlation coefficient (Pearson $r$ ) which used SPSS program Version 25 to investigate the correlation between two independent variables, which were self- control and motivational orientation (Instrumental and Integrative), and the dependent variable, the learners' English achievement considered from the TOEFL score. Likewise, the qualitative one was conducted to explore some additional information to further strengthen the gained quantitative data.

\section{Participants}

The participants involved in this current study were all English Department Students of Hasanuddin University batch 2015 who had attended TOEFL test. From 93 populated participants, there were 32 taken as samples which had considerably fulfilled the required participant for the mixed-method research.

\section{Instruments}

The data resources were TOEFL score result, questionnaire, and in-depth interview. The questionnaires used were Brief Self-Control Scale to measure the participants' self-control, and Gardner's Attitude/Motivation Test Battery (AMTB) for the motivational orientations which both were scrutinized using the Likert Scale [6].

\section{Data Collection}

After obtaining the TOEFL score result of the participants from Pusat Bahasa Unhas, the one arranging the TOEFL test, the researcher distributed the questionnaires to all the participants. There were only 32 of them who responded to 
the questionnaires and gave back to the researcher. To strengthen the data, the researcher also conducted interviews by taking 10 representatives of the participants to gain their perspectives in line with the variables being examined.

\section{Data Analysis}

All the instruments employed were given validity test using SPSS version 25 to ensure that they were distributed evenly or homogeneously in accordance with the involved participants. In terms of the formulas to find out the grand total of the frequency and the percentage of questionnaire items as according to the 32 involved participants, the writer adapted formulas constructed by Gay et al (2006) as below:

$$
p=\frac{F q}{N} \times 100
$$

Where :

$p$ : Percentage from the questionnaire

$\mathrm{Fq}$ : treatment

$N$ : Total Sample

Whereas, to obtain the correlation among variables, the most employed scale of the norm of correlation coefficient was used adapted by calculating through SPSS 25. Moreover, the researcher firstly utilized descriptive analysis to depict all data in chart form, and then it was interpreted in words using inferential analysis. Secondly, the additional information gained from the interview session was analyzed by utilizing qualitative design in order to strengthen and synchronize the validity and reliability of the data elicited from quantitative method.

\section{Findings and Discussion}

\section{Findings}

The Analysis of Motivational Orientations and Self-control

To ensure that the data collection was unbiasedly performed in regard to the distribution of instrumental motivation and self-control questionnaire, below is the normality test of the both participants' motivation:

Table 1. Normality Test of Motivational Orientations and Self-Control

\begin{tabular}{lccc}
\hline & & \multicolumn{2}{c}{ Kolmogorov-Sminorv } \\
\cline { 3 - 4 } Variables & Conf Level & $\mathrm{n}$ & Sig. Value \\
\hline INT Motivation & 0.05 & 32 & 0.2 \\
INS Motivation & 0.05 & 32 & 0.2 \\
Self-Control & 0.05 & 32 & 0.2
\end{tabular}

The following table shows that the significance value of all included variables is higher (0.2) than the confidence level (0.05) indicating that the questionnaires were normally distributed or homogenous throughout the samples.

Table 2. Overall Level of EFL Learners' Motivational Orientations and Self-Control

\begin{tabular}{lclcc}
\hline Variables & Overall mean & Overall level & Standard Deviation & Participants \\
\hline INS & 30.34 & Motivated & 4.35 & 32 \\
INT & 44.53 & Motivated & 4.8 & 32 \\
Self-Control & 46.125 & Self-controlled & 8.72 & 32 \\
\hline
\end{tabular}

Table 2 presents that there is not a significant difference between instrumental and integrative motivation in terms of overall level of categorization; they were all motivated. However, eyeing the overall mean score, both of the motivations are fairly significantly different. Instrumental motivation reached 30.34 while integrative motivation was 44.53. By this data, it can be interpreted that most participants have integrative motivation in learning English. Besides, regarding the standard deviation carried out by the two motivations, the data shows no significant difference, they are all averagely the same in which instrumental SD is 4.35, and 4.8 for the integrative motivation. Therefore, the standard deviation of each motivation was not far deviated from the data without deviation $(\mathrm{SD}=0)$. The data of self-control, on the other hand, shows that the participants' overall scores is 46,125 which is based on the determined classification level used by this present study, it places on the moderate level. Moreover, it can be seen that the 
standard deviation (SD) is 8,76 which means the overall scores of participants' self-control is quite deviated from the data without deviation $(\mathrm{SD}=0)$.

The Analysis of The Correlation between EFL Learners' Achievement and The Two Psychological Aspects: Motivational Orientations and Self-Control

Table 3. The Correlation between EFL Learners' Achievement and The Two Psychological Aspects: Motivational Orientations and Self-Control

\begin{tabular}{|c|c|c|c|c|c|c|c|}
\hline \multirow[b]{2}{*}{$\begin{array}{l}\text { Dependent Vari- } \\
\text { able (Y) }\end{array}$} & \multirow[b]{2}{*}{ Indepedent Variable (X) } & \multirow[b]{2}{*}{$\begin{array}{l}\text { Conf } \\
\text { Level }\end{array}$} & \multirow[b]{2}{*}{$\begin{array}{l}\text { Sig. } \\
\text { Value }\end{array}$} & \multirow[b]{2}{*}{$\begin{array}{l}\text { Correlation Coef- } \\
\text { ficient }(r)\end{array}$} & \multirow[b]{2}{*}{ Category } & \multicolumn{2}{|c|}{ Status of Hypothesis } \\
\hline & & & & & & Ho & $\mathrm{Hi}$ \\
\hline & Instrumental motivation & 0.186 & -0.240 & No correlation & $A$ & $\mathrm{R}$ & \\
\hline \multirow{3}{*}{$\begin{array}{l}\text { EFL Learners } \\
\text { Archievement }\end{array}$} & Integrative motivation & 0.05 & 0.037 & 0.371 & Moderate & $\mathrm{R}$ & A \\
\hline & & & & & & & \\
\hline & Self-control & & 0.002 & 0.542 & Strong & $\mathrm{R}$ & A \\
\hline
\end{tabular}

Table 3 illustrates that from the two examined psychological aspects, motivational orientations and self-control, there is an obvious difference in regard to their correlation with the EFL Learners' achievement. In detail, the correlation goes positive on Integrative motivation ( 0.371 or moderate) and self-control ( 0.542 classified strong) to the English achievement of the learners, and appears negative to the Instrumental Motivation $(-0.240)$ which means no correlation between the investigated variables. It can be in detail proven by the Sig. value from all the variables that Instrumental motivation gains 0.186 is higher than the Conf. Value meaning that the two variables are not significantly correlated. Whereas, Integrative motivation and Self-control show significant correlation with the learners achievement that are 0.037 and 0.002 in respect which both are lower than the Sig. Value (0.05). In result, it can be summed up that integrative motivation is quite contributive, Self-control is strongly contributive, and instrumental motivation has no contribution to the English achievement of the EFL learners. In consequence, the hypothesis examined in this present research is accepted that self-control has a strong correlation with EFL learners' achievement while the integrative and instrumental motivation show moderate and no correlation respectively.

\section{Answers of Research Questions}

In regards to the data presented above, the detailed answers of this present research question, therefore, can be elaborated as follows: 1 ) Is there any correlation between psychological aspect, self-control and motivational orientation, and Learners' English achievement?. Based on the data, it shows that there is a correlation between the psychological aspects and the learners' achievement in English based on their TOEFL score with different distribution of values. To begin with, self-control has a strong correlation (0.532) with the learners' achievement. In addition, regarding significance of data, it shows that both variables are linearly significant as much as 0,002.

Next, the second psychological aspect is motivational orientation. Based on the data, the two motivational orientations have an obvious difference in terms of their correlation with the learners' achievement in TOEFL. Integrative motivation and the achievement was 0,371 categorized as moderate with significance level as much as 0,037 which indicates those two variables have a moderate correlation with linear significance. Besides, the correlation between instrumental motivation and learners' achievement got -0,240 with significance of 0,186 meaning that those variables had no correlation with nonlinear significance.

The second research question is : 2) Which of the two independent variables; self-control and motivational orientation, is more dominant in affecting learners' success in English?. Talking about the dominant variable in predicting learners' English achievement, the elicited data presents that self-control is more dominant that the motivational orientation; whereas the significance values of the correlation of the two psychological aspects and the learners' achievement were various. Integrative motivation and self-control show lower significance (0,037 and 0,002 in its row) than the confidence level $(0,05)$ meaning that there is a significant correlation between the two psychological aspects and the TOEFL score. In the meantime, the other independent variable, instrumental motivation, presented 0,186 in its significance which was higher than the confidence level. That means instrumental motivation does not significantly correlate with the Learners' English achievement.

\section{Discussion}

\section{Learners' Views on English}

From the TOEFL score, it can be seen that the mean level of the participants is on the high intermediate level. This might be underpinned by their views of English spoken up through in-depth interviews, they mostly have a positive position on it. They all believe that English is fundamentally important for their own respective reasons so that 
they undeniably have to put an extra effort to learn it. As an example, one of the interviewees initialized AM, he said that English is vividly important to support his future career. He needs English to help him get connected with other people around the world. In line, some participants also argued that they learned English in order to understand cultures, arts, book, and any other products of the English speaking countries. By these beliefs, they either consciously or unconsciously learn English using their own ways. These arguments are positively relatable with the average TOEFL score of the participants categorized as high intermediate which strongly represents the English competence of the participants.

Even so, in terms of learning English, all participants have heterogeneous points. Some of them said they do not really learn English textually or using an English textbook; they prefer to learn it enjoyably by applying English activities such as listening to English songs, watching movies, chatting with friends in English, or reading contents written in English like articles, magazines, books, and so forth. They revealed that they enjoy doing this a lot rather than getting restricted with English rule patterns. Like the participant initialized, WES positively believed that her English did not come from any English textbook, she got all her improvement by doing those English activities. As an example she added that she never took a bite of learning 16 English tenses, but she could understand how to use them properly.

Besides, the ones who learned English through English textbooks were classified variously. Some of them said they succeeded learning English by understanding the English pattern more specifically, but admitted that it was so time-consuming. While the other participants felt bored learning very textually and at the end they left it without a significant result. More objectively, as the result shows that most of the participants who preferred to learn English through English activities placed up 480 score in total classified as having intermediate level whereas the ones who learned English being tied by the English text book showed lower score down 450 in average.

\section{Learners' Self-Control in Learning English}

Additionally, being controlled of learning English, in fact, showed a significant result based on the answers by some representative participants gained through the interview session. The ones who controllably dealt with English had higher scores than the uncontrolled ones. They averagely got a score up to 480 either the ones learning English textbook, enjoying the English activities, or using both those methods in which the time was consumed like 8 to 10 hours a day. They obtained that competency by unconsciously understanding the pattern of English, like they just got used to it.

To further explain, one of the participants who was interviewed initialized MIN revealed that he was so drawn into an English pattern like the form of English grammar when he was in junior and senior high school. He took serious learning to master it. But, at times, he did not any longer learn it very textually. He made himself get used to English like he enjoyed English through English activities such as listening to English songs, watching movies or videos, playing video games, and doing any other related English activities, and he agreed that his English is far improving compared to his previous strategies; more significantly, he got improved in all English skills. His statement was relatable with his TOEFL score which was 560 categorized advance. Meanwhile, the participants that were categorized as having low scores obviously distributed an equal number of reasons. They stated that they honestly did not really persistently learn English both using textbook and getting used to it in their daily life. In overall, the estimated times that they spent dealing with English only 1 to 2 hours a day including the disturbances while engaging with it. As a representative, a participant initialized $\mathrm{R}$ stated through the interview that she was not really strict in learning English; she just learned the language for specific purposes such as having an English task. Therefore, it can be interpreted that she is not in control when learning English. As a consequence, the score that she gained from the TOEFL test was 423 which is classified as very low intermediate.

Accordingly, although they have the same opinion interpreting English fundamentality and have the same methods to master the language, they still have a clearly different performance in terms of the achievement of English in TOEFL which was strongly affected by the persistence of learning or they tried to control themselves to keep learning the language.. These results of present research were similar with the data elicited by Self-Control and Academic Performance in Engineering which was conducted by Honken, proving that Self-control was respectively influential to students' academic performance [17].

\section{Learners' Motivation in Learning English}

In relation to the reasons for learning English, they were averagely on the same side in which most of them reasoned that they learn English because they like it; they make it as a hobby; or theoretically, most of the participants got integrative motivation. The data in this present research was totally different from the one conducted by Altasan [3] with the same status of participants as being the foreigners of English. He found most of his participants got higher scores in instrumental motivation than integrative one. It was because the participants mostly learned English only to take advantage of it, like for getting a high score of TOEFL in order to achieve a better career in the future. Appositive, in this present research, the participants were more averagely motivated integratively (up to 40) than instrumentally (down 30 in average). As one example, an interviewee initialized RL who scored advance (597), he stated that he learned English because he liked it, he was interested in all things related to English, including English 
speaking community, the arts, music, culture, and so forth which indicate him motivated integratively. It can be proven by the score he gained significantly higher in integrative motivation (51) than the instrumental one (36).

However, this opinion did not only go to the participants having a high score, in fact, it also went to the ones who got lower around 450. Like an interviewee initialized R, she scored 423, but she was motivated higher in integrated motivation (42). She said that she liked English in general, but she just made herself with it while she needed to. She did not really pay attention to learn it. More tellingly, the same opinion came from a participant who initialized NA who had integrative motivation (INT=46, INS=34) but got a lower score (443). It was actually hard to define her motivation in learning English, but in the end she fairly preferred to choose integrative motivation; even so, her achievement in TOEFL was not quite in line with the motivation that she had. This might considerably be underpinned by the self-control that was only scored 34 categorized uncontrolled. To add, in the interview, she said that she found it hard to keep herself learning English although she believed that her English is waiting for improvement. Even though she had already had the motivation, she still could not find a way to make herself keep on learning the language.

Furthermore, there were also participants that were not able to put themselves in either instrumental or integrative motivation. They just prefer both. It can be seen from the score, a few of the participants scored both motivations in a way incomparable. As an example, a participant initialized EL put herself interchangeably at both motivations. She said that she preferred to choose both because she liked English but she could not deny she needed it for supporting her career as an English student. Unfortunately, her score on TOEFL was 460, which was low in intermediate. It might be triggered by her persistence of learning English (self-control) was only 22 in which based on the categorization list, she was categorized strongly uncontrolled. To support, she said that she rarely learned English or stayed with English activities. Even though she had once taken an English course, she left it without any significant improvement.

\section{Final Analysis of the Correlation between Psychological Aspects, Motivational Orientations and Self-Control, and Learners' Achievement in English}

Therefore, it can be inferred as a whole both from the descriptive numeric data and the interview ones, motivation and self-control have a clear fundamental role to support participants' English achievements portrayed in the TOEFL score. Although they have motivation to learn English, self-control or the persistence of learning persistence is far more influential than just being motivated. It can be seen from the interview that most participants agreed having motivation without a persistent effort (self-control) will not give a positive impact to the learners. Linearly, an interviewee initialized AM saying that he more referred to be on self-control side because he had once strived for it. He tried to be persistent to learn English, and the result was vividly progressive. He could see his improvement in his English by doing the persistence of learning. He also added that motivation is such a gate to go to a target goal, but self-control indeed is the bridge to guide us to the goals. In further, he believed that by keeping in mind that we have the motivation means we are not motivated yet, we just force that we have the motivation. Yet, by just doing it happily without thinking too much whether we have the motivation or not, we can reach what we want. It is appreciated as an important factor to organize students towards achieving their academic grade.

More detail, these two psychological aspects do not really show a significant difference in result, they both have correlation with learners' achievement in TOEFL. Even though the correlation data reveals that self- control has a strong correlation $(0,542)$ with the TOEFL score, and has a moderate correlation $(0,371)$, they still have positive correlation one another, unless the instrumental motivation that showed negative correlation $(-0,240)$ meaning no correlation at all between that motivation and the achievement. It occurs because as displayed in the interview, most of the participants' scores were clearly linear between the self-control and TOEFL score which means the more controlled the participant is, the better the TOEFL score is. On the other hand, in regard to the motivational orientations, the findings were various. There were some participants who got high scores in integrative motivation, but got lower TOEFL score, or vice versa. To further elaborate, there was a participant who initialized A who was highly motivated integratively (51), but got an intermediate TOEFL score (480). To compare, a participant initialized RL got an advanced score in TOEFL (597), but had the same score of motivation as the previous participant (51). To strengthen, some of the interviewees at the first time found it hard to choose which one of them is more important to have because they both have their own role in affecting the English achievement. But mostly went to self-control with quite insignificant reason compared to the motivations.

\section{Conclusion}

According to the data from this present research, it was found that the English achievement depicted in the TOEFL score was considered as high intermediate $(M=485.15)$ with Self-control owned categorized moderate $(M=46.125)$. In regard to the motivational orientation of the participants, the data showed that all participants were motivated with difference in the mean score. Instrumental Motivation had 30.34 whereas integrative motivation mean score was 44.53. Hence, it can be confidently inferred that most participants were motivated integratively. 
As in relative, self-control has a strong correlation with learners' TOEFL score $(r=0.532)$ meaning that there is a strong effect carried out by self- control in determining the English learners' success. Besides, the significant value is lower than the confidence level $(0,05)$ which was 0.002 indicating there is only $5 \%$ that might cause mistakes during the data collection. Meanwhile, the correlation between both motivational orientations brought a great difference. Integrative motivation has a positive correlation ( $r=0.371)$ with the learners' English achievement although classified as moderate. While the instrumental one showed negative correlation $(r=-0.240)$ which was further categorized not having correlation at all. This means that integrative motivation has a relative contribution to learners' English achievement that the instrumental one. It was also supported by the significant values which showed lower than the confidence level $(0,05)$; Sig. INT =0,037), whereas the significant level of instrumental motivation showed higher than confidence level (Sig, INS =0.186) meaning that both instrumental motivation and TOEFL achievement were not significantly correlated. Those proofs mean that the inaccuracy of data was only about $5 \%$ and the accuracy was 95\% using two- tailed.

By this evidence, it can be summed, therefore, that the answer of research question number 1 was that there is a correlation between the psychological aspects, self-control and motivational orientations, and learners' English achievement. However, from both aspects, there were only self-control (strong) and integrative motivation (moderate) having correlation with the achievement; while instrumental motivation showed no correlation. Henceforth, it can be strongly interpreted that self-control has a more dominant role in affecting the learners' success in learning the language with correlation value (0,532 or categorized as strong).

\section{References}

[1] P. Yan, Chrysthania, "A positive impact of being part time English toward ALESP Students' motivation to learn English", A Bachelor Thesis. Sanata Dharma University, 2017.

[2] Zanghar, Ahmad, "Instrumental and Integrative Motivation among Undergraduate Libyan Students of English as a Foreign Language", Master Degree Thesis. Colorado State University, 2012.

[3] A. M. B, Altasan, "Motivational orientations and their effect on English Language Learning: A Study in EFL Saudi Context," American Journal of Educational Research, vol.4, pp. 1131-1137, Jan. 2016.

[4] Job, Veronica, F, Malte and Katharina Bernecker, "Effects of Practicing Self-control on Academic Performance", Motivation Science, vol.1, pp. 219-232, May, 2016.

[5] Duckworth, L. Angela, D. Q. Patrick and T. Eli Tsuk, "What No Child Left Behind Leaves Behind: The Roles of IQ and Self-Control in Predicting Standardized Achievement Test Scores and Report Card Grades", J Educ Psychol, vol.104, pp. 439-451, 1 May, 2012

[6] R. C. Gardner, Social psychology and second language learning: The role of attitudes and motivation, London: Edward Arnold Publishers, 1985.

[7] Z. Dörnyei and R. Schmidt, Motivation and second language acquisition, University of Hawaii, 2002.

[8] L. Gliksman, R. C. Gardner and P. C. Smythe, "The role of the integrative motive on students' participation in the French classroom", Canadian Modern Language Review, vol.38, pp. 625-647, 4 May, 1982.

[9] D. Lasagabster, A. Doiz and J.M. Sierra, Motivation and Foreign language learning: from theory to practice. Amsterdam: John Benjamins, 2014.

[10] Z. Dorney, Conceptualizing Motivation in Foreign Language Learning. Language Learning, 40 45-78, 22 February 1990

[11] R. Ellis, The study of second language acquisition. Oxford: Oxford University, 1994.

[12] Z. Dörnyei, The Psychology of The Language Learner: Individual Differences in Second Language Acquisition. Lawrence Erlbaum Associates, Inc. Mahwah: New Jersey, 2005.

[13] Choosri, Chalermporn and I. Usa, "Relationship between Motivation and Students' English Learning Achievement: A study of the Second - year vocational certificate level Hatyai Technical College Students" presented at The $3^{\text {rd }}$ International Conference on Humanities and Social Sciences, pp. 1-15, 2 April, 2011.

[14] P. Li and G. Pan, "The relationship between motivation and achievement - a survey of the study motivation of English majors in Qingdao agricultural University", English Language Teaching, vol. 2, pp. 123-128, Feb, 2009

[15] Duckworth, L. Angela, L. Jamie, Taxer, E. W. Lauren, M. G. Brian, J. G. James, "Self-Control and Academic Achievement", Annual Review of Psychology.373-399. 2019. 
[16] J. W. Creswell, Research Design: Qualitative, Quantitative, and mixed methods approach $4^{\text {th }}$ edition. Thousand Oaks, CA: Sage, 2013.

[17] Honken, Nora, A. R. Patricia, and R.T. Thomas, "Self-Control and Academic Performance in Engineering", American Journal of Engineering .Education, vol. 2, pp. 47-57, Dec, 2016. 